\title{
The effects of testosterone on bone health in males with testosterone deficiency: a systematic review and meta-analysis
}

\author{
Zhichao Zhang ${ }^{1}$, Deying Kang ${ }^{2}$ and Hongjun $\mathrm{Li}^{\mathrm{i}^{*}}$
}

\begin{abstract}
Background: Testosterone deficiency (TD) may induce a series of clinical symptoms. Studies have shown that testosterone supplementation may prevent these unfavourable symptoms and improve patients' quality of life. Given the conflicting findings across studies, this systematic review aims to evaluate the effects and risks associated with testosterone supplementation in middle-aged or aging males with TD.

Methods: Electronic databases (MEDLINE, EMBASE, PubMed, and Cochrane. Library were searched to December 2019. The risk of bias of individual included studies and the quality of the aggregate evidence were assessed using the GRADE approach. Our primary outcome was bone mineral density (BMD). Meta-analyses were performed. This systematic review was reported according to the PRISMA statement.

Results: A total of 52 randomized controlled trials (RCTs) were included. When compared with placebo, testosterone supplementation did not increase total BMD (short-term: 1081 participants, MD $-0.01 \mathrm{~g} / \mathrm{cm}^{2}, 95 \% \mathrm{Cl}-$ $0.02 \mathrm{~g} / \mathrm{cm}^{2}$ to $0.01 \mathrm{~g} / \mathrm{cm}^{2}$; long-term: 156 participants, MD $0.04 \mathrm{~g} / \mathrm{cm}^{2}, 95 \% \mathrm{Cl}-0.07 \mathrm{~g} / \mathrm{cm}^{2}$ to $0.14 \mathrm{~g} / \mathrm{cm}^{2}$ ), lumbar spine, hip, or femur neck BMD. Furthermore, testosterone supplementation did not decrease the risk of falling or fracture. Lastly, it was found that testosterone supplementation did not increase the risk of cardiovascular events (1374 participants, RR 1.28, 95\% Cl 0.62 to 2.64), all-cause mortality (729 participants, RR $0.55,95 \%$ Cl 0.29 to 1.04 ), or prostatic events. However, testosterone supplementation may improve sexual function and quality of life (1328 participants, MD -1.32, 95\% Cl - 2.11 to -0.52 ).

Conclusions: The effect of testosterone supplementation on BMD and the risk of falls or fracture remains inconclusive. However, supplementation may benefit patients in the areas of sexual function and quality of life without increasing the risk of cardiovascular events, all-cause mortality, or prostatic events. RCTs with a longer follow-up period are still required.
\end{abstract}

Trial registration: We registered our protocol in PROSPERO (CRD42018109738).

Keywords: Testosterone, Aging, Males, Testosterone deficiency, Systematic review

\section{Background}

Aging is associated with a $1 \%$ decline in testosterone levels in males, though the causes remain unclear [1]. Testosterone deficiency (TD) refers to a low level of serum testosterone and may induce a series of clinical symptoms [2]. Androgen deficiency may lead to dysfunctions of the

\footnotetext{
* Correspondence: lihongjun@pumch.cn

${ }^{3}$ Urological Department of Peking Union Medical College Hospital (PUMCH), Peking Union Medical College, Chinese Academy of Medical Sciences, No. 1 Shuaifu, Eastern District, Beijing 100730, China

Full list of author information is available at the end of the article
}

skeletal, reproductive, and cardiovascular systems. Patients with TD also seem to be at higher risk of sustaining fractures ${ }^{3 .}$ An epidemiological study [3] of 50,613 patients with prostate cancer who survived for at least five years reported a higher incidence of fractures in patients who received androgen-deprivation therapy (ADT) than in patients who did not $(19.4 \%$ versus $12.6 \%, p<0.001)$.

Given the association between TD and fracture revealed by the observational studies mentioned above, it is believed that androgen supplementation therapy can prevent osteoporosis and increase bone mass. However,

(c) The Author(s). 2020 Open Access This article is distributed under the terms of the Creative Commons Attribution 4.0 International License (http://creativecommons.org/licenses/by/4.0/), which permits unrestricted use, distribution, and 
several randomized controlled trials (RCTs) failed to demonstrate that testosterone supplementation increases bone density in patients with TD [4-6]. Furthermore, clinicians have also expressed concern about other associated risks of prescribing testosterone to middle-aged or aging patients with TD, especially the risk of cardiovascular and prostatic events [7-11]. Whether testosterone supplementation increases the risk of cardiovascular events remains a focus of debate. Two large cohort studies $[9,10]$ reported that testosterone therapy increases the risk of myocardial infarction. One RCT that enrolled 209 patients [11] also reported that the application of testosterone gel was associated with an increased risk of cardiovascular events. However, in another RCT [8], the authors found that the use of testosterone did not increase the risk of carotid artery intima-media thickness or coronary artery calcium in 308 men 60 years or older with low or low-normal testosterone levels.

There is also uncertainty among clinicians about whether testosterone supplementation in aging males is protective against other risks, such as all-cause mortality and prostate cancer. Although several systematic reviews $[7,12-15]$ on this topic have been published, they did not fully address the above questions $[7,12,13]$. While one review [13] investigated the effect of testosterone replacement on patients' quality of life, it did not investigate the effect of testosterone replacement on bone mineral density (BMD), cardiovascular disease, and all-cause mortality. Three reviews [14-16] evaluated the efficacy of testosterone therapy in males with late-onset hypogonadism $(\mathrm{LOH})$ and found that testosterone increased BMD. However, these reviews were either out of date or they omitted relevant studies; several RCTs reported no effect of testosterone on BMD after these reviews $[17,18]$ were published. Given these conflicting results, an update of the evidence regarding the impact of testosterone supplementation on BMD is required. Two systematic reviews investigated the risk of cardiovascular events after testosterone therapy, but the findings were inconsistent. One review [8] found that testosterone therapy increases the risk of cardiovascular events in aging males, while the other review [16] simply made reference to the controversy surrounding this issue. Given that the evidence to date is both conflicting and insufficient, this systematic review aims to evaluate the effect of testosterone supplementation on BMD and its potential risks (fracture, falling, allcause mortality, cardiovascular disease, and prostate events) in middle-aged or aging males with TD.

\section{Methods}

\section{Materials and methods}

We registered our protocol in PROPERO (CRD420181 09738). The systematic review and meta-analysis (study level) were conducted in alignment with the Cochrane
Handbook of Interventional Reviews and reported in accordance with the PRISMA standard.

\section{Inclusion and exclusion criteria}

Aging male adults (aged $\geq 40$ years old) with a diagnosis of TD were included in this review. Because of the lack of a uniform definition of TD, we accepted any criteria used in the included studies to define TD. We only included studies involving patients with TD who were not interested in fertility and who were determined to have well-controlled obstructive sleep apnoea syndrome (OSAS). Any RCT in which testosterone therapy was used alone or in combination with other therapies (such as calcium or vitamin D) were included without restrictions regarding treatment dosage, frequency, and duration. Testosterone therapy might have included oral capsules, gels, patches, injections, pellets, sublingual testosterone. The comparator was placebo. The exclusion criteria were i) studies including patients with prostatic cancer who had received castration therapy (including endocrine therapy or testectomy) or androgen therapy; ii) studies including patients with testicular cancer; iii) studies including patients with primary hypogonadism induced by pituitary disease or pituitary surgery; iv) studies including patients with secondary hypogonadism (e.g., Paltauf's dwarfism, pituitary tumour, acromegalia, or Cushing's syndrome); and v) studies including patients who received other medications that influence androgen levels (e.g., finasteride, sildenafil).

Our primary outcome was total BMD. Secondary outcomes included lumbar spine BMD, total hip BMD, or other BMDs, the incidence rates of hip fracture, falling, total fracture, vertebral or non-vertebral fracture, all-cause mortality, and cardiovascular events (defined as myocardial infarction, angina, coronary artery disease, hypertension, stroke, or other definitions used in the original studies), as well as quality of life, total cost, sexual function, adverse events, prostate-specific antigen (PSA) level, and prostate events, such as prostate cancer or prostatitis.

\section{Searching and study screening}

We conducted electronic searches in MEDLINE, Cochrane Library, EMBASE and PubMed on 9 December 2019. The search strategy was developed by an information specialist and is presented in Additional file 1. There was no limitation on language, document type, and publication status. We also hand searched the references of relevant systematic reviews to identify additional RCTs for inclusion. Two reviewers screened the search results. Disagreements were resolved by discussion with assistance from a third party if necessary.

\section{Data extraction and synthesis}

Data from each study were extracted independently by two separate reviewers using a standardized data extraction 
form. Any disagreements were resolved by discussion with the assistance from a third party if necessary.

We synthesized data using a fixed-effect method for all analyses. An $\mathrm{I}^{2}$ estimate greater than or equal to $50 \%$ accompanied by a statistically significant $\chi^{2}$ statistic was interpreted as evidence of a substantial level of heterogeneity. Where substantial heterogeneity was found, we explored potential sources that may have caused this heterogeneity. If we could not definitively locate the sources of heterogeneity, we synthesized the data using a random-effects model. We summarised all dichotomous outcome data using risk ratios (RRs) and all continuous outcome data using mean differences (MDs) and calculated their respective 95\% confidence intervals (CIs).

\section{Risk of bias assessment}

We made the risk of bias judgments based on the methods endorsed by The Cochrane Collaboration, which included the following domains: patient allocation, blinding, selective reporting, attrition of study participants, and any other detected sources of bias [19].

\section{Additional analysis}

We assessed the quality of the body of evidence for the primary and secondary outcomes based on the GRADE approach [20]. To test the robustness of the results of the synthesis, we conducted a trial sequential analysis (TSA) [21] for the primary outcomes. The required information size (RIS) was calculated based on the empirical mean difference and variance with a two-sided alpha of 0.05 and a beta of 0.20 [21].

\section{Results}

Study screening and characteristics of included studies

In total, 2637 references were screened, and 69 articles derived from 52 studies [4-6, 11, 17, 18, 22-67] were included after inspecting the full texts. The study screening process and the reasons for the exclusion of full texts are presented in Fig. 1. Fifty-two studies with 5067 participants met our study selection criteria. The study sample size ranged from 10 to 362 . The average age of the participants ranged from 52 to 77.1 years, with BMIs ranging from 22.9 to 37.4 . As reported in the included

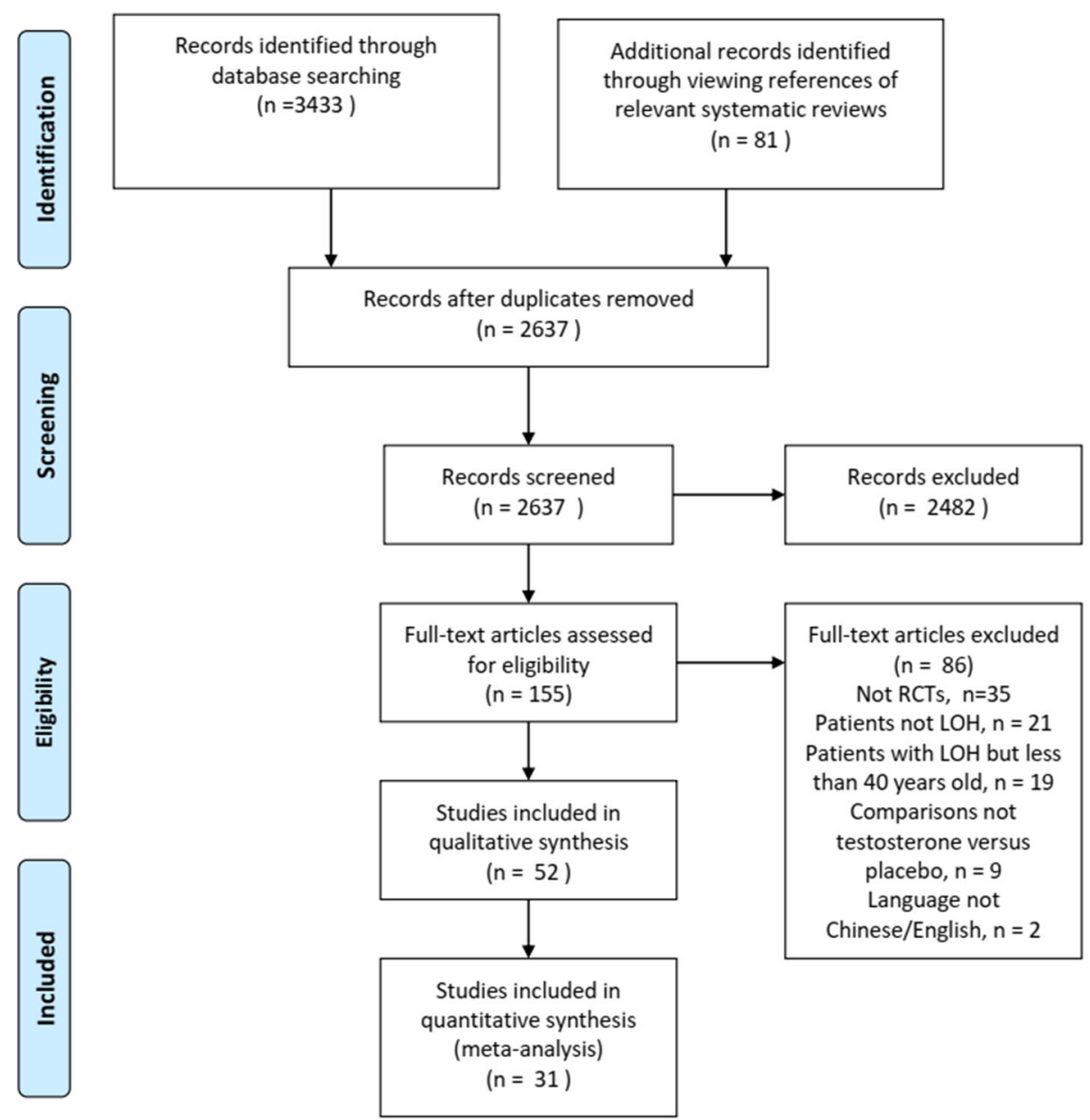

Fig. 1 Study screening flow diagram, Notes: ${ }^{*} 52$ studies with 69 companion full-text articles 
studies, there were 276 (5.45\%) participants with CAD at baseline, $212(4.18 \%)$ participants with dyslipidaemia or hyperlipidaemia, 261 (4.26\%) participants with metabolic syndrome, 761 (15.02\%) participants with diabetes mellitus, 419 (8.27\%) participants with hypertension, 12 (0.24\%) participants with prostatic disease, 186 (3.67\%) participants with osteoporosis, 31 (0.61\%) participants with osteoarthritis, and $57(1.12 \%)$ participants with a history of fracture. Patient characteristics are summarized in Additional file 2.

\section{Risk of bias}

Figure 2 shows the overall results of the risk of bias of the included studies. The process of randomization was rated as low risk of bias in half of the included studies. With regard to blinding, $71 \%$ of the included studies stated that the participants and personnel were blinded to the treatment protocol. Twenty-nine studies were rated as low risk of bias in the domain of incomplete outcome data' because of the low attrition rate. Sixteen studies were rated as high risk of attrition bias, as the attrition rate was higher than $20 \%$ of the total sample size. Most studies (63\%) were rated as low risk of bias in the 'selective reporting domain' because all measured outcomes were reported.

\section{Estimate of effect}

Due to insufficient data, only a subgroup analysis of the treatment duration was conducted. We grouped all the included studies into short-term treatment duration $(<2$ years) and long-term treatment duration ( $\geq 2$ years).

\section{BMD}

Ten RCTs [5, 6, 17, 18, 23, 36, 42, 48, 54, 68] reported this outcome. The results showed, when compared with placebo, testosterone supplementation did not increase total BMD in both the short-term (less than 2 years of treatment) (8 RCTs, 1081 participants, MD $-0.01 \mathrm{~g} / \mathrm{cm}^{2}$, $95 \% \mathrm{CI}-0.02 \mathrm{~g} / \mathrm{cm}^{2}$ to $0.01 \mathrm{~g} / \mathrm{cm}^{2}$, low quality of evidence) and the long-term (more than 2 years of treatment) (2 RCTs, 156 participants, MD $0.04 \mathrm{~g} / \mathrm{cm}^{2}, 95 \%$ CI $-0.07 \mathrm{~g} / \mathrm{cm}^{2}$ to $0.14 \mathrm{~g} / \mathrm{cm}^{2}$, very low quality of evidence) (Fig. 3, Table 1). This outcome showed significant heterogeneity, but we were unable to identify the cause of heterogeneity. The optimal sample size for total BMD for the short- and long-term groups were 9310 and 1776, respectively (Additional file 3).

This nonsignificant effect was also observed for lumbar spine BMD (short-term: 7 RCTs [6, 17, 18, 36, 42, 48, 68], 719 participants, MD $0.00 \mathrm{~g} / \mathrm{cm}^{2}, 95 \%$ CI -0.02 $\mathrm{g} / \mathrm{cm}^{2}$ to $0.02 \mathrm{~g} / \mathrm{cm}^{2}$; long-term: 2 RCTs [23, 54], 156 participants, MD $0.04 \mathrm{~g} / \mathrm{cm}^{2}, 95 \%$ CI $-0.07 \mathrm{~g} / \mathrm{cm}^{2}$ to $0.14 \mathrm{~g} / \mathrm{cm}^{2}$, Fig. 4), hip BMD (short-term: 5 RCTs [17, $18,36,42,48], 651$ participants, MD $0.00 \mathrm{~g} / \mathrm{cm}^{2}, 95 \% \mathrm{CI}$ $-0.02 \mathrm{~g} / \mathrm{cm}^{2}$ to $0.03 \mathrm{~g} / \mathrm{cm}^{2}$; long-term: 2 RCTs [23, 54], 156 participants, MD $0.03 \mathrm{~g} / \mathrm{cm}^{2}, 95 \% \mathrm{CI}-0.01 \mathrm{~g} / \mathrm{cm}^{2}$ to $0.07 \mathrm{~g} / \mathrm{cm}^{2}$, Fig. 5) and femur neck BMD (short-term: 3 RCT s $[6,18,68], 274$ participants, MD $0.00 \mathrm{~g} / \mathrm{cm}^{2}, 95 \%$ $\mathrm{CI}-0.02 \mathrm{~g} / \mathrm{cm}^{2}$ to $0.02 \mathrm{~g} / \mathrm{cm}^{2}$, Fig. 6).

\section{Incidence rate of fracture}

One RCT [18] reported the incidence rate of fracture. No significant difference was found between the groups (short-term, 211 participants, RR 0.92, 95\% CI 0.31 to 2.76; low quality of evidence, Table 1). No study reported the incidence rate of fracture in specific bone sites, such as the hip or vertebrae.

\section{Incidence rate of falling}

One RCT [56] reported the incidence rate of falling. The results showed no significant difference between the groups (short-term, 262 participants, RR 0.70, 95\% CI 0.34 to 1.45 ; low quality of evidence, Table 1 ).

\section{All-cause mortality}

Five RCTs $[41-43,59,67]$ reported this outcome. The results showed that when compared with placebo, testosterone supplementation decreased the risk of all-

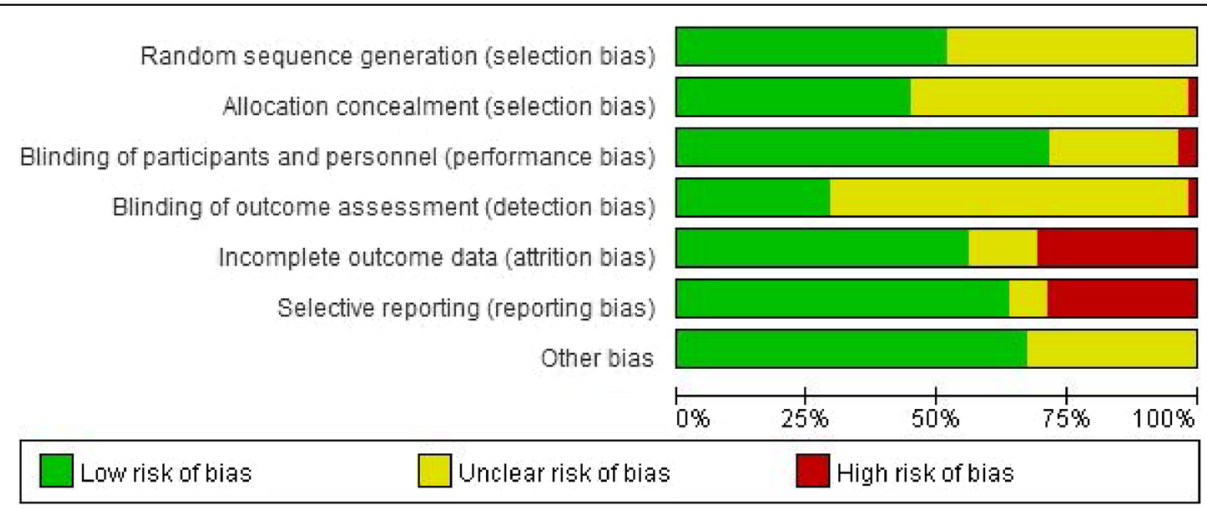

Fig. 2 Risk of bias assessment 


\begin{tabular}{|c|c|c|c|c|c|c|c|c|c|c|c|}
\hline \multirow{3}{*}{$\begin{array}{l}\text { Study or Subqroup } \\
\text { 1.1.1 short term }\end{array}$} & \multicolumn{3}{|c|}{ Testosterone therapy } & \multicolumn{2}{|c|}{ Placebo } & \multirow[b]{2}{*}{ Total } & \multirow[b]{2}{*}{ Weiqht } & \multirow{2}{*}{$\begin{array}{l}\text { Mean Difference } \\
\text { IV, Random, } 95 \% \mathrm{Cl}\end{array}$} & \multirow{2}{*}{\multicolumn{3}{|c|}{$\begin{array}{l}\text { Mean Difference } \\
\text { IV, Random, } 95 \% \mathrm{Cl}\end{array}$}} \\
\hline & Mean & SD & Total & Mean & $\mathrm{SD}$ & & & & & & \\
\hline & \\
\hline Behre 2012 & 1.2 & 0.1353 & 183 & 1.22 & 0.1338 & 179 & $19.0 \%$ & $-0.02[-0.05,0.01]$ & & & \\
\hline Dias 2015 & 0.042 & 0.0288 & 13 & 0.047 & 0.013 & 9 & $45.9 \%$ & $-0.00[-0.02,0.01]$ & & & \\
\hline Emmelot-Vonk 2008 & 1.23 & 0.2 & 113 & 1.23 & 0.2 & 110 & $5.3 \%$ & $0.00[-0.05,0.05]$ & & & \\
\hline Fui 2018 & 1.25 & 0.3947 & 44 & 1.26 & 0.1521 & 38 & $0.9 \%$ & $-0.01[-0.14,0.12]$ & & & \\
\hline Kenny 2001 & 1.217 & 0.113 & 24 & 1.227 & 0.08 & 20 & $4.5 \%$ & $-0.01[-0.07,0.05]$ & & & \\
\hline Kenny 2010 & 1.16 & 0.087 & 53 & 1.153 & 0.092 & 46 & $11.6 \%$ & $0.01[-0.03,0.04]$ & & & \\
\hline Merza 2006 & 1.05 & 0.19 & 20 & 1.018 & 0.1 & 19 & $1.6 \%$ & $0.03[-0.06,0.13]$ & & & \\
\hline Snyder 2017 & 1.2 & 0.19 & 109 & 1.19 & 0.2 & 101 & $5.2 \%$ & $0.01[-0.04,0.06]$ & & & \\
\hline Subtotal $(95 \% \mathrm{Cl})$ & & & 559 & & & 522 & $94.0 \%$ & $-0.01[-0.02,0.01]$ & & & \\
\hline \multicolumn{12}{|c|}{$\begin{array}{l}\text { Heterogeneity: } \text { Tau }^{2}=0.00 ; \mathrm{Chi}^{2}=2.53, \mathrm{df}=7(\mathrm{P}=0.92) ; \mathrm{I}^{2}=0 \% \\
\text { Test for owerall effect: } Z=0.80\left(\mathrm{P}^{\mathrm{P}}=0.42\right)\end{array}$} \\
\hline \multicolumn{12}{|l|}{ 1.1.2 long term } \\
\hline Amory 2004 & 1.16 & 0.1895 & 24 & 1.06 & 0.1895 & 24 & $1.3 \%$ & $0.10[-0.01,0.21]$ & & & \\
\hline Snyder 1999 & 1.232 & 0.15 & 54 & 1.241 & 0.145 & 54 & $4.7 \%$ & $-0.01[-0.06,0.05]$ & & & \\
\hline Subtotal $(95 \% \mathrm{Cl})$ & & & 78 & & & 78 & $6.0 \%$ & $0.04[-0.07,0.14]$ & & & \\
\hline \multicolumn{12}{|c|}{$\begin{array}{l}\text { Heterogeneity: } \text { Tau }^{2}=0.00 ; C h i^{2}=3.13, d f=1(P=0.08) ; l^{2}=68 \% \\
\text { Test for overall effect: } Z=0.66(P=0.51)\end{array}$} \\
\hline \multirow{2}{*}{\multicolumn{3}{|c|}{$\begin{array}{l}\text { Total }(95 \% \mathrm{Cl}) \\
\text { Heterogeneity: } \mathrm{Tau}^{2}=0.00 ; \mathrm{Chi}^{2}=6.21 \text {, df }= \\
\text { Test for awerall effect: } \mathrm{Z}=0.64(\mathrm{P}=0.52) \\
\text { Test for subaroun differences: } \mathrm{Chi}^{2}=0.56 \text {. }\end{array}$}} & \multicolumn{2}{|c|}{637} & & 600 & $100.0 \%$ & $-0.00[-0.02,0.01]$ & & & \\
\hline & & & $\begin{array}{l}9(P=0 \\
A f=1(P\end{array}$ & $\begin{array}{l}0.72) ; 1^{2}= \\
=0.45)\end{array}$ & $\begin{array}{l}=0 \% \\
1^{2}=0 \%\end{array}$ & & & & $\begin{array}{r}1 \\
-0.2\end{array}$ & \multicolumn{2}{|c|}{$\begin{array}{cccc}-0.1 & 0 & 0.1 & 0.2 \\
\text { Favours [Placebo] } & \text { Favours [Testosterone] }\end{array}$} \\
\hline \multicolumn{12}{|c|}{ Fig. 3 Testosterone versus placebo: Meta-analysis of total BMD } \\
\hline
\end{tabular}

cause mortality, however, the difference was not statistically significant (5 RCTs [41-43, 59, 67], 729 participants, RR 0.55, 95\% CI 0.29 to 1.04; Fig. 7), either in the short-term (low quality of evidence, Table 1) and the long-term (Fig. 7; very low quality of evidence, Table 1).

\section{Incidence of cardiovascular event}

Ten RCTs with 12 references [11, 17, 36, 40, 41, 49, 54, $59,66,67,69,70]$ reported this outcome. The results showed no significant difference in the risk of cardiovascular events between the placebo and testosterone supplementation groups (1374 participants, RR 1.28, 95\% CI 0.62 to 2.64 ). This outcome showed significant heterogeneity $\left(\mathrm{I}^{2}=72 \%\right)$, which was induced by one study [40]. However, after comparing variables, such as patient characteristics, different types of testosterone, and treatment duration between this and the other studies, we failed to identify the specific source of heterogeneity. There was no significant difference between groups both in the short- and long-term subgroup analysis (Fig. 8; low quality of evidence, Table 1).

\section{Quality of life}

Eight RCTs [5, 39, 41, 43, 50, 56, 59, 63] measured this outcome using the Aging Males' Symptoms (AMS) scale. The results demonstrated that testosterone supplementation improved patients' quality of life in the short-term (1328 participants, MD -1.32 , 95\% CI -2.11 to -0.52 , Additional file 4; moderate quality of evidence, Table 1).

\section{Sexual function}

Four RCTs [39, 41, 59, 65] measured this outcome by using the International Index of Erectile Function-5 (IIEF-5) scale. The results demonstrated that testosterone supplementation improved sexual function in the short-term (503 participants, MD 1.48, 95\% CI 0.05 to 2.91, Additional file 5). This outcome had a significant level of heterogeneity. After exploring the sources, we found that Tan 2013 [54] was an outlier, but we could not identify the specific causes for the heterogeneity. The quality of evidence was low (Table 1).

\section{Adverse events}

Eight RCTs with nine references $[5,32,36,43,55,56$, $59,66,69]$ reported the total number of adverse events between the testosterone supplementation and placebo groups. No significant difference between the groups was found in each study, except for Tan 2013 who reported a lower incidence of adverse events in the testosterone group. Due to the heterogeneity found in the total adverse events across studies, we did not pool the data in the meta-analysis (Additional file 6).

\section{PSA level}

Fifteen RCTs $[4,5,23,31,33,36,42,46,50,52,54,56$, $59,60,71]$ showed a slightly higher serum PSA level in the testosterone supplementation group (1514 participants, MD 0.15, 95\% CI 0.04 to 0.27, Additional file 7). This difference was observed in the short- but not the long-term (Additional file 7). Six RCTs also reported the risk of PSA among the groups, but no significant 


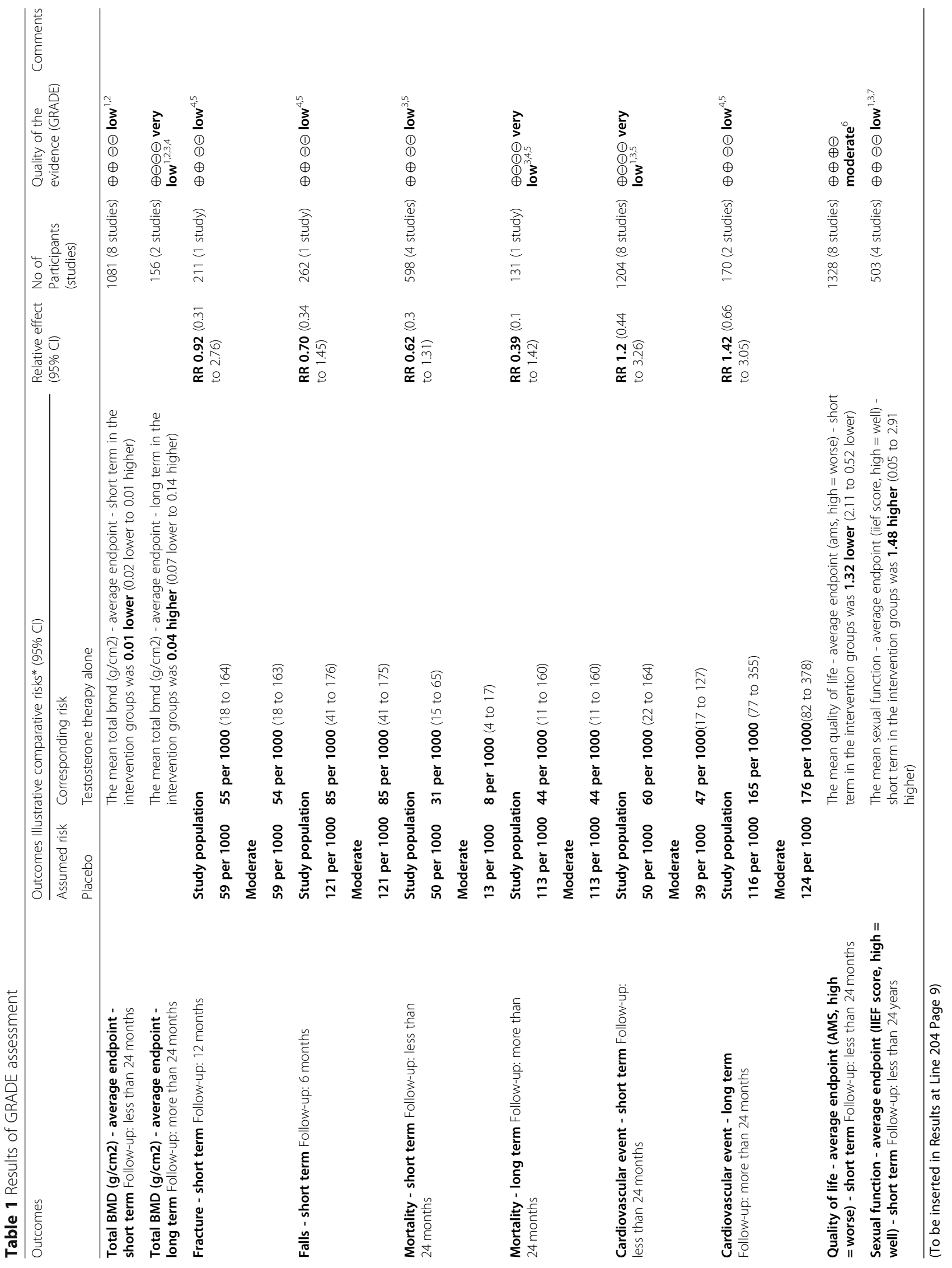




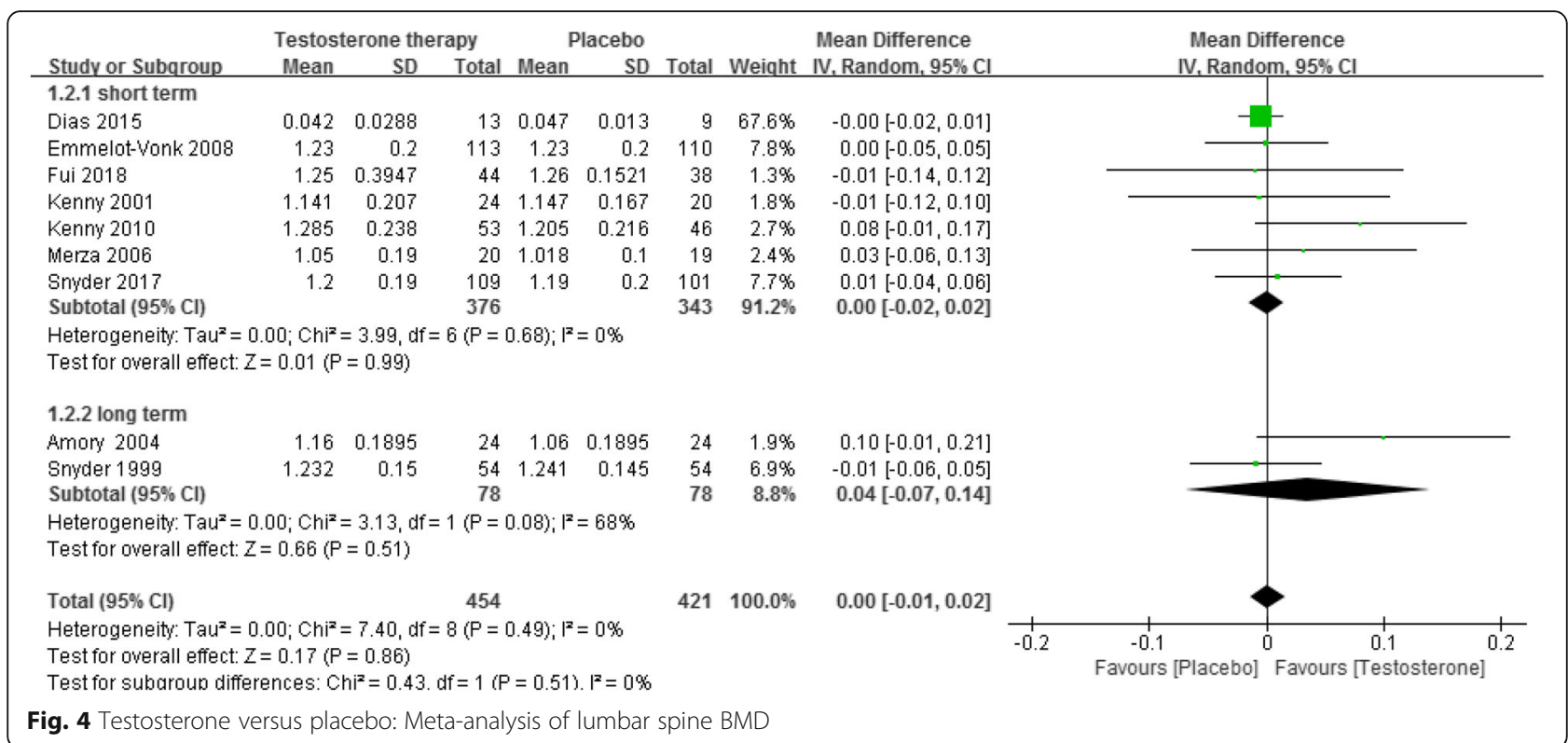

difference was found between the groups (1090 participants, RR 1.14, 95\% CI 0.71 to 1.81, Additional file 8).

\section{Prostate events}

One study [54] reported the incidence rate of prostate events in the placebo and testosterone supplementation groups. The prostate events included prostatitis, prostate nodule, prostate cancer, and PSA increase. No significant difference was found between the groups (1 RCT, 108 participants, RR 1.45 , 95\% CI 0.75 to 2.84 ).

\section{Discussion}

This review included 5067 participants with TD. Evidence showed that compared with placebo, testosterone supplementation did not i) increase total BMD, vertebral, hip and femoral BMD; ii) decrease the risk of falling or fracture; or iii) increase the risk of cardiovascular events, allcause mortality or prostatic events, such as PSA increase or prostatitis; however, testosterone supplementation was associated with improved quality of life and sexual function. Nonetheless, the above findings may be influenced by the presence of attrition bias and selective reporting in individual RCTs. Furthermore, the small total sample size and the unexplained heterogeneity between studies also impacted the quality of the body of evidence, especially for long-term outcomes and the risk of cardiovascular events. In terms of sexual function and quality of life, the indirect approach used to interpret the results of the screening tools somewhat reduces our level of confidence in these findings. All the included studies used surrogate outcome

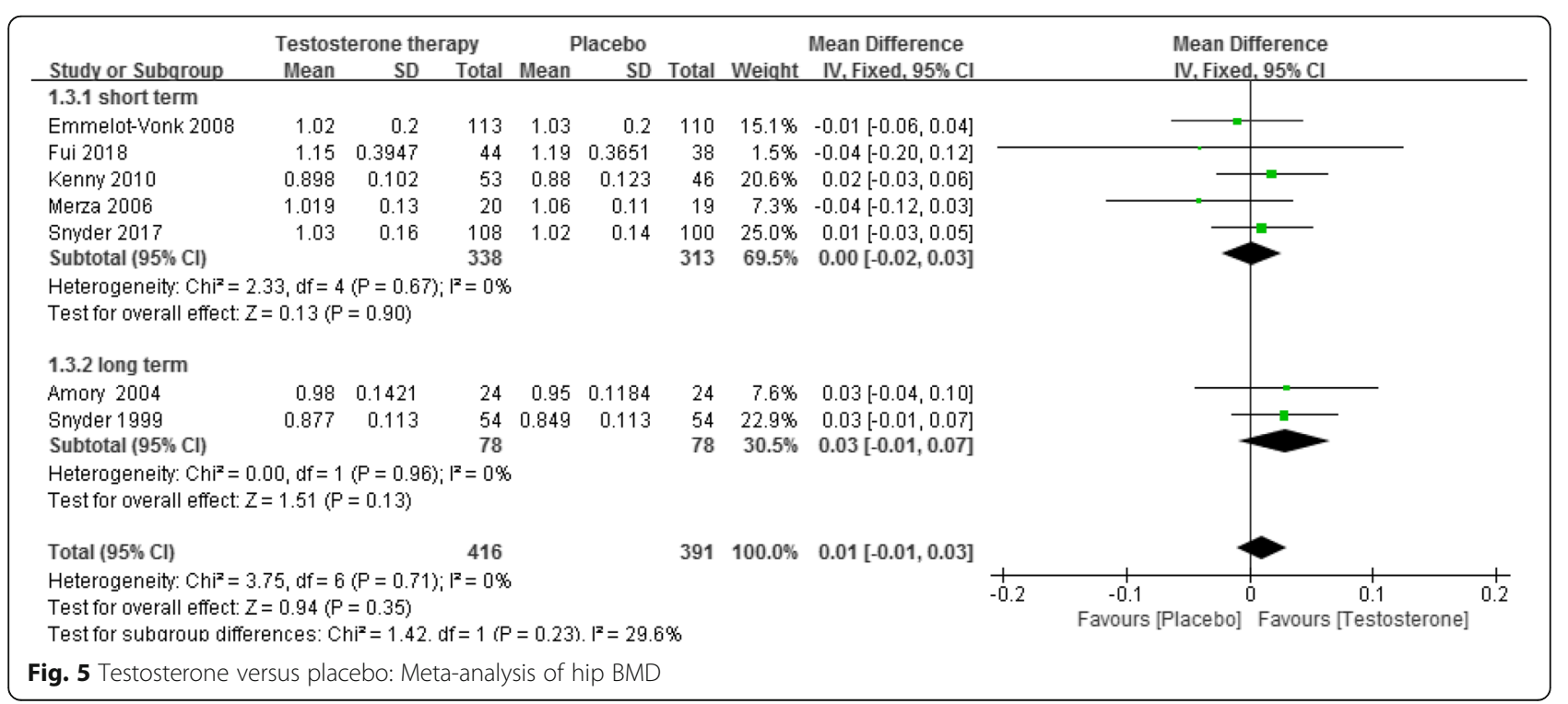




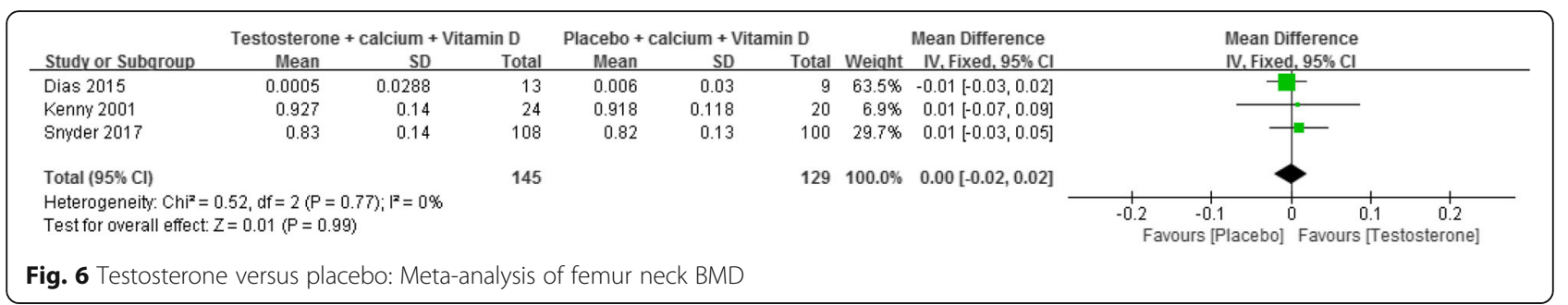

measurements, namely the mean difference in the scores of each scale, to reflect improvement in these two outcomes. However, clinicians must also consider whether the differences in the scores between the two compared groups are clinically significant.

Testosterone receptors are widely distributed in bone tissues. When combined with these receptors, testosterone facilitates skeletal growth and development, for instance by stimulating the proliferation of preosteoblasts and the differentiation of osteoblasts (non-dependent oestrogen conversion) and by promoting the maturation and ossification of cartilage cells and deposits of calcium on bone [72]. Theoretically, testosterone supplementation can improve bone health in patients with TD. However, the current meta-analysis failed to demonstrate this effect, a finding that is consistent with previous systematic reviews [15, 73-75]. Contrary to our findings, a guideline published in 2010 [76] stated that although testosterone had no effect on vertebral, hip and femoral BMD, it was associated with an increase in lumbar BMD. A possible reason for this inconsistent finding is that this guideline focused on patients with osteoporosis, while we included only a very small proportion of participants with osteoporosis. Nonetheless, even with our negative finding, there are several reasons why caution must be exercised in concluding that testosterone does not affect BMD. First, the finding that testosterone supplementation did not improve BMD in the short-term $(<2$ years) may due to inadequate duration of treatment. It is well known that the effect of testosterone on BMD is only evident after more than 2 years of use. However, only 156 participants from two studies used testosterone for $>2$ years, and the sample size is too small to detect a significant difference between the groups. Second, although all participants were androgen deficient, most did not have any abnormality in bone mass density or any evidence of osteoporosis at baseline; therefore, the change in BMD before and after testosterone supplementation may be nonsignificant. We also did not find any difference in the risk of fall or fracture between the testosterone supplementation and the placebo groups, though this may also be due to inadequate treatment duration and the small sample size.

Several studies $[7,9,11]$ indicated that testosterone increases the risk of cardiovascular events. However, we did not find this effect in our meta-analysis, possibly because only a small proportion (5.45\%) of participants in our review had a history of CAD at baseline, while

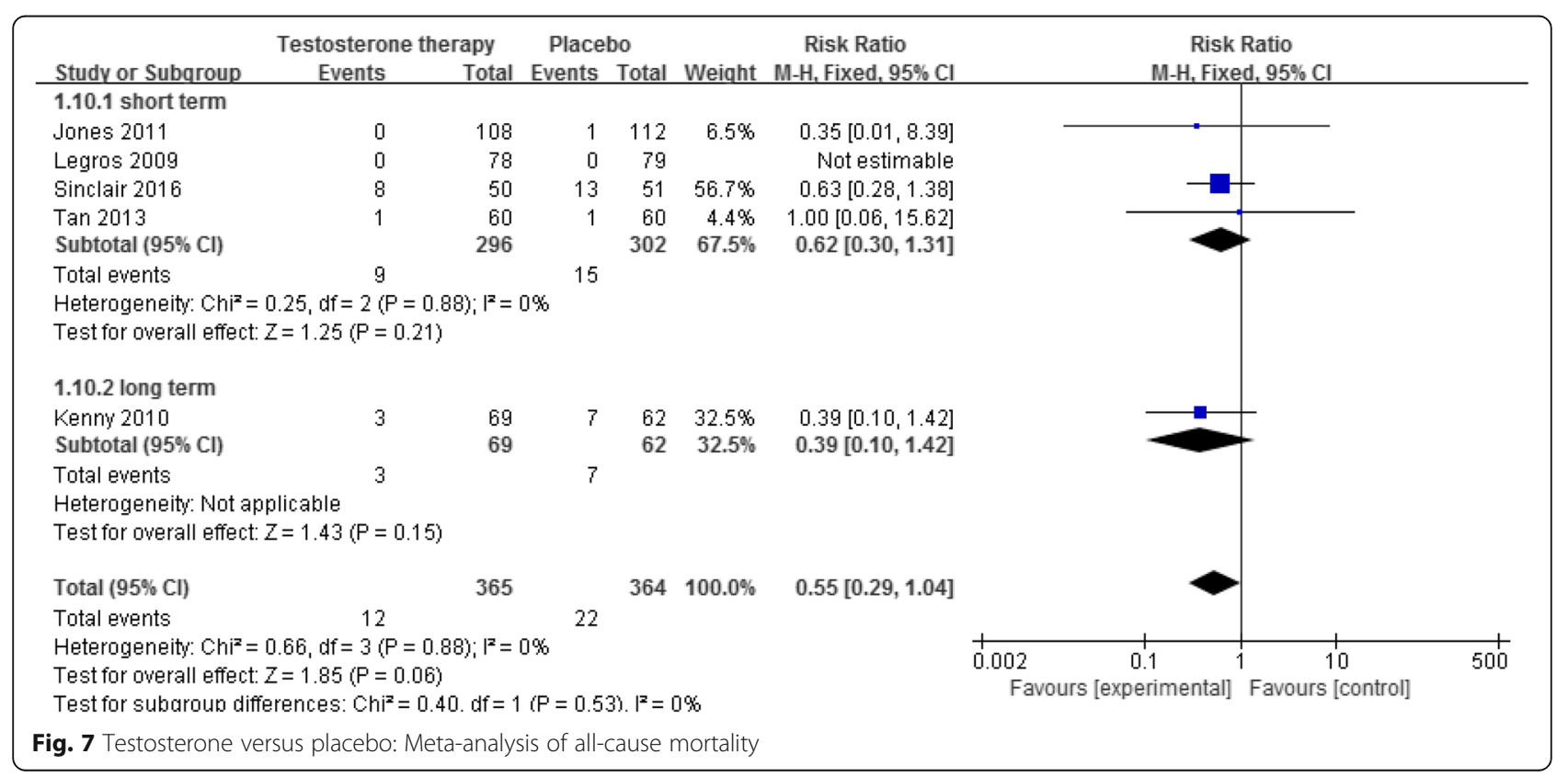




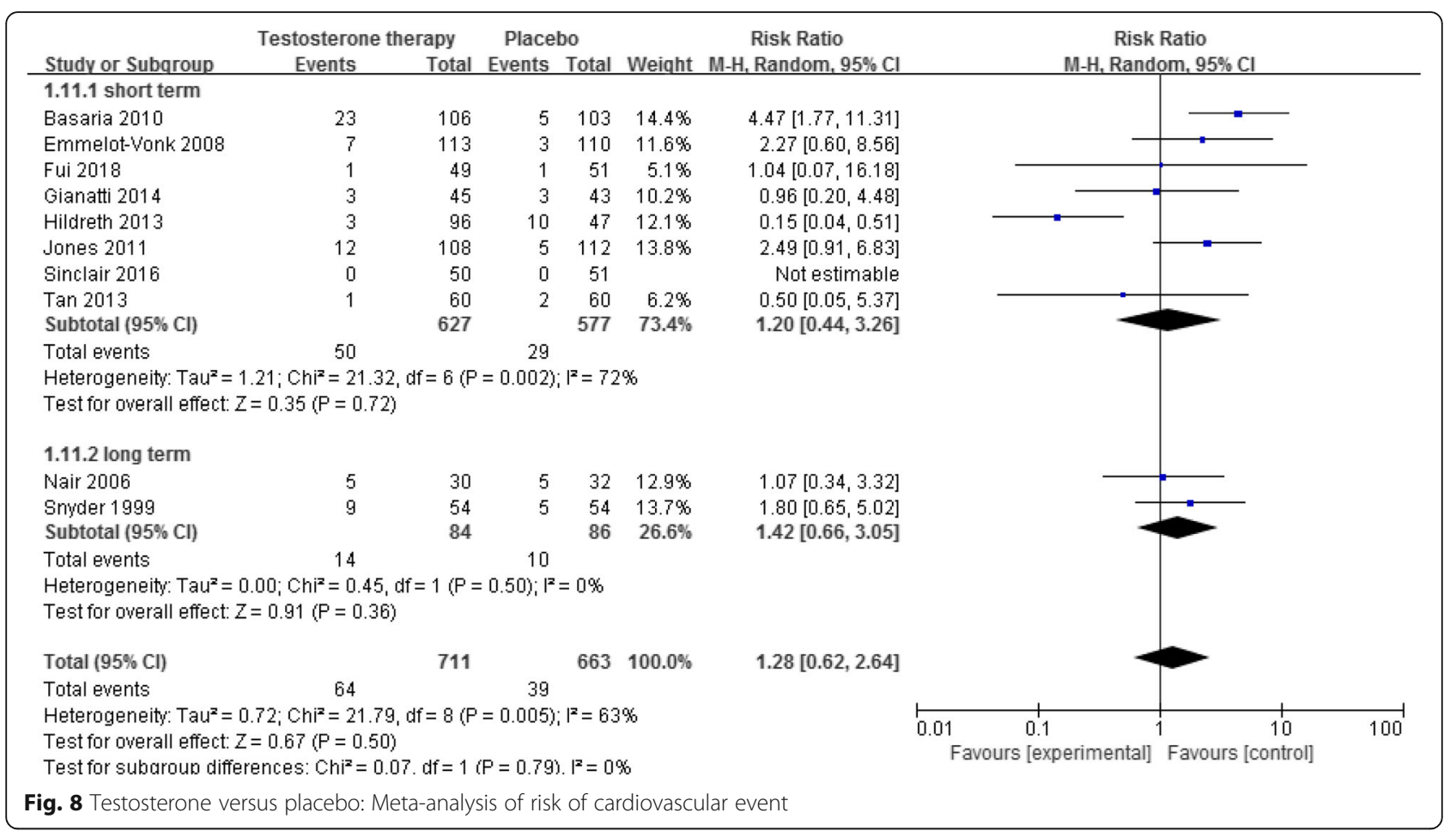

several studies [9-11] included a larger number of patients with a history of CAD. Furthermore, the age range of participants also differs between our review and the above studies, with the latter including participants older than 60 years compared with our inclusion of participants over 40 years of age. One cohort study [10] indicated that a history of CAD and an age greater than 65 years were risk factors for cardiovascular events in patients treated with testosterone.

With regard to all-cause mortality, our review found that testosterone did not decrease the risk of all-cause mortality in patients with TD. We concluded that this negative result was due to inadequate sample size, as there was an obvious trend towards a reduction in the rate of all-cause mortality in the testosterone supplementation group; however, the $95 \%$ confidence interval was too wide to detect a significant difference. While this result is consistent with another review [72] in which testosterone supplementation was found not to increase the incidence of severe adverse events, including mortality, it is contrary to the finding reported in a cohort study of a positive association between testosterone supplementation and all-cause mortality [10]. These inconsistent findings may in part be explained by the variations in the baseline characteristics of the participants, especially the differences in ages and associated comorbidities. More RCTs are clearly needed to better identify the effect of testosterone supplementation on mortality.
Three studies $[12,13,77]$ found that testosterone therapy increases sexual function in patients with a low testosterone level, which is consistent with our finding. We also found improved quality of life in the testosterone therapy group. However, one study did not find this favourable effect [76]. In that study [76], the included participants had complex comorbidities, which may explain this difference. In our meta-analysis fewer participants had comorbidities, and thus, a significant improvement in quality of life may have been more evident.

Persistent concerns revolve around whether testosterone supplementation increases the risk of prostate cancer or BPH. Consistent with other observational studies [78-80], this review did not find an association between testosterone supplementation and prostate cancer. Interestingly, subnormal testosterone levels have been reported to be associated with highgrade prostate cancer [81].

This systematic review has some strengths. First, the search strategy was developed by a professional information specialist. In addition, we searched both electronic databases and hand searched the references of relevant systematic reviews. This approach allowed us to collect as many relevant RCTs as possible. Second, the study screening and data extraction process were conducted by two researchers independently to minimize bias.

The systematic review also has some limitations. For instance, the long-term data for primary or secondary 
outcomes were insufficient to detect a clear difference between the groups. Furthermore, significant heterogeneity between populations was identified, such as the definition of TD or $\mathrm{LOH}$ and differences in the presence of comorbidities at baseline. Despite the presence of significant heterogeneity, we were unable to determine whether the variations in the effect of testosterone supplementation across subgroup populations were due to insufficient data.

\section{Conclusion}

\section{Implications for practice}

The effect of testosterone supplementation on BMD and on the risk of falling or fracture in patients with TD remains inconclusive. However, testosterone supplementation may improve sexual function and quality of life without increasing the risk of CAD, all-cause mortality, and prostate diseases.

\section{Implications for research}

Further research is needed with RCTs that adequately report methods used for generating random allocation sequences. Larger RCTs with long-term data on the effect of testosterone supplementation on BMD, risk of fracture or falling, CAD, and all-cause mortality are required. Lastly, RCTs are also needed that focus on our predefined subgroup population of TD patients, such as those between 40 and 65 years of age as well as patients with osteoporosis or a history of CAD.

\section{Supplementary information}

Supplementary information accompanies this paper at https://doi.org/10. 1186/s12902-020-0509-6.

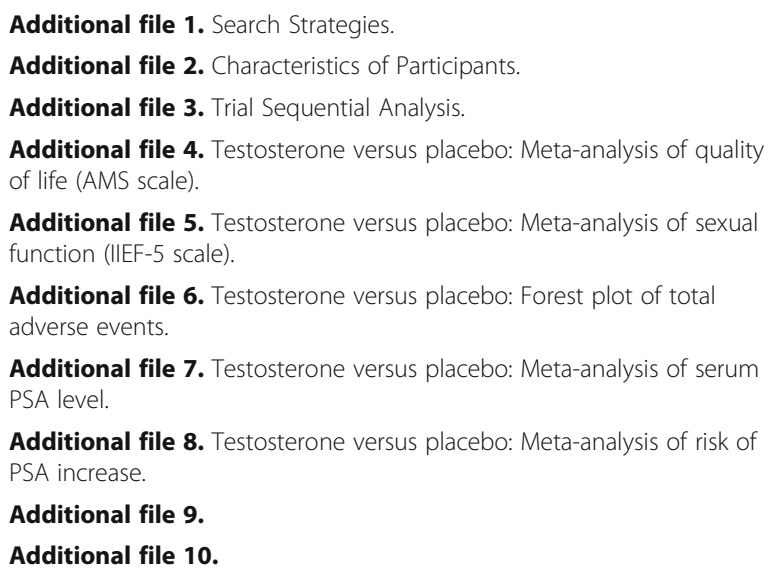

Additional file 7. Testosterone versus placebo: Meta-analysis of serum PSA level.

Additional file 8. Testosterone versus placebo: Meta-analysis of risk of PSA increase.

Additional file 9.

Additional file 10 .

\section{Abbreviations}

ADT: Androgen-deprivation therapy; AMS: Aging Males' Symptoms; BMD: Bone mineral density; CAD: Cardiovascular disease; Cls: Confidence intervals; IIEF-5: International Index of Erectile Function-5; MDs: Mean differences; PSA: Prostate specific antigen; RCT: Randomized controlled trial; RIS: Required information size; RR: Risk ratio; TD: Testosterone deficiency; TSA: Trial sequential analysis

\section{Acknowledgements}

We would like to thank Miss Sai Zhao from Systematic Review Solutions. Ltd. for collection and assembly of data and editorial assistance, and Margueritte White M.D. for language editing assistance. We also would like to thank Miss Fang Qi for biostatistician consultant.

\section{Authors' contributions}

Study design: HJL and DYK. Data analysis: ZZ, HJL and DYK. Data interpretation: ZZ and HJL. Drafting manuscript: ZZ and HJL. Revising manuscript content: HJL. Approving final version of manuscript: HJL. HJL takes responsibility for the integrity of the data analysis. All Authors read and approved this section.

\section{Funding}

Assistance for collection and assembly of data and editorial assistance were provided by SRS, which was funded by MSD China. MSD had no role in design of the study, collection, analysis, and interpretation of data or in writing the manuscript.

\section{Availability of data and materials}

The datasets used and/or analysed during the current study are available from the corresponding author upon reasonable request.

Ethics approval and consent to participate

Not applicable.

\section{Consent for publication}

Not applicable.

\section{Competing interests}

The authors declare that they have no competing interests.

\section{Author details}

${ }^{1}$ Andrology Center, Department of Urology, Peking University First Hospital; Institute of Urology, Peking University, No 8 Xishenku Street, Beijing 100034, China. ${ }^{2}$ Department of Evidence based Medicine and Clinical Epidemiology, West China Hospital, Sichuan University, No. 37 Guoxuexiang, Chengdu 610041, China. ${ }^{3}$ Urological Department of Peking Union Medical College Hospital (PUMCH), Peking Union Medical College, Chinese Academy of Medical Sciences, No. 1 Shuaifu, Eastern District, Beijing 100730, China.

Received: 31 December 2019 Accepted: 14 February 2020 Published online: 07 March 2020

\section{References}

1. Feldman HA, Longcope C, Derby CA, et al. Age trends in the level of serum testosterone and other hormones in middle-aged men: longitudinal results from the Massachusetts male aging study. J Clin Endocrinol Metab. 2002; 87(2):589-98.

2. McBride JA, Carson CC, Coward RM. Diagnosis and management of testosterone deficiency. Asian J Androl. 2015;17(2):177-86.

3. Shahinian VB, Kuo YF, Freeman JL, Goodwin JS. Risk of fracture after androgen deprivation for prostate cancer. New Engl J of Med. 2005;352(2):154-64.

4. Kenny AM, Prestwood KM, Gruman CA, et al. Effects of transdermal testosterone on lipids and vascular reactivity in older men with low bioavailable testosterone levels. J Gerontol A-Biol. 2002;57(7):M460-5.

5. Behre HM, Tammela TL, Arver S, et al. A randomized, double-blind, placebocontrolled trial of testosterone gel on body composition and health-related quality-of-life in men with hypogonadal to low-normal levels of serum testosterone and symptoms of androgen deficiency over 6 months with 12 months open-label follow-up. Aging Male. 2012;15(4):198-207.

6. Dias JP, Melvin D, Simonsick EM, et al. Effects of aromatase inhibition vs. testosterone in older men with low testosterone: randomized-controlled trial. Andrology. 2016;4(1):33-40.

7. Xu L, Freeman G, Cowling BJ, Schooling CM. Testosterone therapy and cardiovascular events among men: a systematic review and meta-analysis of placebo-controlled randomized trials. BMC Med. 2013;11:108.

8. Basaria S, Harman SM, Travison TG, et al. Effects of testosterone administration for 3 years on subclinical atherosclerosis progression in older men with Low or Low-Normal testosterone levels: a randomized clinical trial. Jama. 2015;314(6):570-81. 
9. Finkle WD, Greenland S, Ridgeway GK, et al. Increased risk of non-fatal myocardial infarction following testosterone therapy prescription in men. PLoS One. 2014;9(1):e85805.

10. Vigen $\mathrm{R}, \mathrm{O}$ 'Donnell $\mathrm{Cl}$, Baron $\mathrm{AE}$, et al. Association of testosterone therapy with mortality, myocardial infarction, and stroke in men with low testosterone levels. Jama. 2013;310(17):1829-36.

11. Basaria S, Coviello AD, Travison TG, et al. Adverse events associated with testosterone administration. New Engl J of Med. 2010;363(2):109-22.

12. Gruenewald DA, Matsumoto AM. Testosterone supplementation therapy for older men: potential benefits and risks. J Am Geriatr Soc. 2003;51(1):101-15.

13. Nian $Y$, Ding M, Hu S, et al. Testosterone replacement therapy improves healthrelated quality of life for patients with late-onset hypogonadism: a meta-analysis of randomized controlled trials. Andrologia; 2017. https:/doi.org/10.1111/and.12630.

14. Tracz MJ, Sideras K, Bolona ER, et al. Testosterone use in men and its effects on bone health. A systematic review and meta-analysis of randomized placebo-controlled trials. J Clin Endocr Metab. 2006;91(6):2011-6.

15. Isidori AM, Giannetta E, Greco EA, et al. Effects of testosterone on body composition, bone metabolism and serum lipid profile in middle-aged men: a meta-analysis. Clin Endocrinol. 2005;63(3):280-93.

16. Corona G, Rastrelli G, Forti G, Maggi M. Update in testosterone therapy for men. J Sex Med. 2011;8(3):639-54

17. Ng Tang Fui M, Hoermann R, Nolan B, et al. Effect of testosterone treatment on bone remodelling markers and mineral density in obese dieting men in a randomized clinical trial. Sci Rep. 2018;8(1):9099.

18. Snyder PJ, Kopperdahl DL, Stephens-Shields AJ, et al. Effect of testosterone treatment on volumetric bone density and strength in older men with Low testosterone: a controlled clinical trial. JAMA Intern Med. 2017;177(4):471-9.

19. Higgins JP, Altman DG, Gotzsche PC, et al. The Cochrane Collaboration's tool for assessing risk of bias in randomised trials. BMJ (Clinical research ed.). 2011;343:d5928.

20. Guyatt G, Oxman AD, Akl EA, et al. GRADE guidelines: 1. IntroductionGRADE evidence profiles and summary of findings tables. J Clin Epidemiol. 2011;64(4):383-94.

21. Wetterslev J, Jakobsen JC, Gluud C. Trial sequential analysis in systematic reviews with meta-analysis. BMC Med Res Methodol. 2017;17(1):39.

22. Agledahl I, Brodin E, Svartberg J, Hansen JB. Impact of long-term testosterone treatment on plasma levels of free TFPI and TF-induced thrombin generation ex vivo in elderly men with low testosterone levels. J Thromb Haemost. 2009;102(5):945-50.

23. Amory JK, Watts NB, Easley KA, et al. Exogenous testosterone or testosterone with finasteride increases bone mineral density in older men with low serum testosterone. J Clin Endocrinol Metab. 2004;89(2): 503-10.

24. Arlt W. Can dehydroepiandrosterone or testosterone replacement effectively treat the symptoms of aging? Nat Clinl Practi Endoc. 2007;3(6):448-9.

25. Aversa A, Isidori AM, Spera G, et al. Androgens improve cavernous vasodilation and response to sildenafil in patients with erectile dysfunction. Clin Endocrinol. 2003;58(5):632-8.

26. Basurto L, Zarate A, Gomez $\mathrm{R}$, et al. Effect of testosterone therapy on lumbar spine and hip mineral density in elderly men. Aging Male. 2008; 11(3):140-5.

27. Borst SE, Yarrow JF, Conover CF, et al. Musculoskeletal and prostate effects of combined testosterone and finasteride administration in older hypogonadal men: a randomized, controlled trial. Am J Physiol Endocrinol Metab. 2014;306(4):E433-2.

28. Boyanov MA, Boneva Z, Christov VG. Testosterone supplementation in men with type 2 diabetes, visceral obesity and partial androgen deficiency. Aging Male. 2003;6(1):1-7.

29. Buvat J, Montorsi F, Maggi M, et al. Hypogonadal men nonresponders to the PDE5 inhibitor tadalafil benefit from normalization of testosterone levels with a $1 \%$ hydroalcoholic testosterone gel in the treatment of erectile dysfunction (TADTEST study). J Sex Med. 2011:8(1):284-93.

30. Casaburi R, Bhasin S, Cosentino L, et al. Effects of testosterone and resistance training in men with chronic obstructive pulmonary disease. Am J Resp Crit Care. 2004;170(8):870-8.

31. Cavallini G, Caracciolo S, Vitali G, et al. Carnitine versus androgen administration in the treatment of sexual dysfunction, depressed mood, and fatigue associated with male aging. Urology. 2004;63(4):641-6.

32. Christmas C, O'Connor KG, Harman SM, et al. Growth hormone and sex steroid effects on bone metabolism and bone mineral density in healthy aged women and men. J Gerontol A-Biol. 2002;57(1):M12-8.
33. Clague JE, Wu FC, Horan MA. Difficulties in measuring the effect of testosterone replacement therapy on muscle function in older men. Int J Androl. 1999;22(4):261-5.

34. Del Fabbro E, Garcia JM, Dev R, et al. Testosterone replacement for fatigue in hypogonadal ambulatory males with advanced cancer: a preliminary double-blind placebo- diabetes care. Support Care Cancer. 2013;21(9):2599-25607.

35. Dias JP, Veldhuis JD, Carlson O, et al. Effects of transdermal testosterone gel or an aromatase inhibitor on serum concentration and pulsatility of growth hormone in older men with age-related low testosterone. Metabolism. 2017;69:143-7.

36. Emmelot-Vonk MH, Verhaar HJ, Nakhai Pour HR, et al. Effect of testosterone supplementation on functional mobility, cognition, and other parameters in older men: a randomized controlled trial. Jama. 2008;299(1):39-52.

37. Fennell C, Sartorius G, Ly LP, et al. Randomized cross-over clinical trial of injectable vs. implantable depot testosterone for maintenance of testosterone replacement therapy in androgen deficient men. Clin Endocrinol. 2010;73(1):102-9.

38. Frederiksen L, Hojlund K, Hougaard DM, et al. Testosterone therapy increased muscle mass and lipid oxidation in aging men. Age (Dordrecht, Netherlands). 2012:34(1):145-56.

39. Hackett G, Cole N, Bhartia M, et al. Testosterone replacement therapy improves metabolic parameters in hypogonadal men with type 2 diabetes but not in men with coexisting depression: the BLAST study. J Sex Med. 2014;11(3):840-56.

40. Hildreth $\mathrm{KL}$, Barry DW, Moreau KL, et al. Effects of testosterone and progressive resistance exercise in healthy, highly functioning older men with low-normal testosterone levels. J Clin Endocrinol Metab. 2013;98(5):1891-900.

41. Jones TH, Arver S, Behre HM. Bt al. Testosterone replacement in hypogonadal men with type 2 diabetes and/or metabolic syndrome (the TIMES2 study). Diabetes Care. 2011;34(4):828-37.

42. Kenny AM, Kleppinger A, Annis K, et al. Effects of transdermal testosterone on bone and muscle in older men with low bioavailable testosterone levels, low bone mass, and physical frailty. J Am Geriatr Soc. 2010;58(6):1134-43.

43. Legros JJ, Meuleman EJ, Elbers JM, et al. Oral testosterone replacement in symptomatic late-onset hypogonadism: effects on rating scales and general safety in a randomized, placebo-controlled study. Eur J Endocrinol. 2009;160(5):821-31.

44. Liu PY, Yee B, Wishart SM, et al. The short-term effects of high-dose testosterone on sleep, breathing, and function in older men. J Clin Endocrinol Metab. 2003;88(8):3605-13.

45. Maggio M, Snyder PJ, Ceda GP, et al. Is the haematopoietic effect of testosterone mediated by erythropoietin? The results of a clinical trial in older men. Andrology. 2013;1(1):24-8.

46. Marks LS, Mazer NA, Mostaghel E, et al. Effect of testosterone replacement therapy on prostate tissue in men with late-onset hypogonadism: a randomized controlled trial. Jama. 2006;296(19):2351-61.

47. Meier C, Liu PY, Ly LP, et al. Recombinant human chorionic gonadotropin but not dihydrotestosterone alone stimulates osteoblastic collagen synthesis in older men with partial age-related androgen deficiency. J Clin Endocrinol Metab. 2004:89(6):3033-41.

48. Merza Z, Blumsohn A, Mah PM, et al. Double-blind placebo-controlled study of testosterone patch therapy on bone turnover in men with borderline hypogonadism. Int J Androl. 2006;29(3):381-91.

49. Nair KS, Rizza RA, O'Brien P, et al. DHEA in elderly women and DHEA or testosterone in elderly men. N Engl J Med. 2006;355(16):1647-59.

50. Shigehara K, Sugimoto K, Konaka H, et al. Androgen replacement therapy contributes to improving lower urinary tract symptoms in patients with hypogonadism and benign prostate hypertrophy: a randomised controlled study. Aging Male. 2011;14(1):53-8.

51. Shores MM, Kivlahan DR, Sadak TI, et al. A randomized, double-blind, placebo-controlled study of testosterone treatment in hypogonadal older men with subthreshold depression (dysthymia or minor depression). J Clin Psychiat. 2009;70(7):1009-16.

52. Sih R, Morley JE, Kaiser FE, et al. Testosterone replacement in older hypogonadal men: a 12-month randomized controlled trial. J Clin Endocrinol Metab. 1997;82(6):1661-7.

53. Simon D, Charles MA, Lahlou N, et al. Androgen therapy improves insulin sensitivity and decreases leptin level in healthy adult men with low plasma total testosterone: a 3-month randomized placebo-controlled trial. Diabetes Care. 2001;24(12):2149-51. 
54. Snyder PJ, Peachey $H$, Hannoush $\mathrm{P}$, et al. Effect of testosterone treatment on bone mineral density in men over 65 years of age. J Clin Endocrinol Metab. 1999;84(6):1966-72.

55. Spitzer M, Basaria S, Travison TG, et al. Effect of testosterone replacement on response to sildenafil citrate in men with erectile dysfunction: a parallel, randomized trial. Ann Intern Med. 2012;157(10):681-91.

56. Srinivas-Shankar U, Roberts SA, Connolly MJ, et al. Effects of testosterone on muscle strength, physical function, body composition, and quality of life in intermediate-frail and frail elderly men: a randomized, double-blind, placebo-controlled study. J Clin Endocrinol Metab. 2010;95(2):639-50.

57. Stout M, Tew GA, Doll H, et al. Testosterone therapy during exercise rehabilitation in male patients with chronic heart failure who have low testosterone status: a double-blind randomized controlled feasibility study. Am Heart J. 2012;164(6):893-901.

58. Tan RS, Pu SJ. A pilot study on the effects of testosterone in hypogonadal aging male patients with Alzheimer's disease. Aging Male. 2003;6(1):13-7.

59. Tan WS, Low WY, Ng CJ, et al. Efficacy and safety of long-acting intramuscular testosterone undecanoate in aging men: a randomised controlled study. BJU Int. 2013;111(7):1130-40.

60. Vaughan C, Goldstein FC, Tenover JL. Exogenous testosterone alone or with finasteride does not improve measurements of cognition in healthy older men with low serum testosterone. J Androl. 2007;28(6):875-82.

61. Wang YJ, Zhan JK, Huang W, et al. Effects of low-dose testosterone undecanoate treatment on bone mineral density and bone turnover markers in elderly male osteoporosis with low serum testosterone. Int. 2013; 2013:570413.

62. Wittert GA, Chapman IM, Haren MT, et al. Oral testosterone supplementation increases muscle and decreases fat mass in healthy elderly males with low-normal gonadal status. J Gerontol A-Biol. 2003;58(7):618-25.

63. Atkinson RA, Srinivas-Shankar U, Roberts SA, et al. Effects of testosterone on skeletal muscle architecture in intermediate-frail and frail elderly men. J Gerontol A-Biol. 2010;65(11):1215-9.

64. Aversa A, Bruzziches R, Francomano D, et al. Effects of testosterone undecanoate on cardiovascular risk factors and atherosclerosis in middleaged men with late-onset hypogonadism and metabolic syndrome: results from a 24-month, randomized, double-blind, placebo-controlled study. J Sex Med. 2010;7(10):3495-4503.

65. Aversa A, Bruzziches R, Francomano D, et al. Efficacy and safety of two different testosterone undecanoate formulations in hypogonadal men with metabolic syndrome. J Endocrinol Inves. 2010;33(11):776-83.

66. Gianatti EJ, Dupuis $P$, Hoermann $R$, et al. Effect of testosterone treatment on glucose metabolism in men with type 2 diabetes: a randomized controlled trial. Diabetes Care. 2014;37(8):2098-107.

67. Sinclair M, Gow $\mathrm{P}$, Grossmann $\mathrm{M}$, et al. The effect of testosterone therapyon muscle mass, bone mass and haemoglobin in hypogonadal men with cirrhosis. J Hepatol. 2016;1:S140-S1.

68. Kenny AM, Prestwood KM, Gruman CA, et al. Effects of transdermal testosterone on bone and muscle in older men with low bioavailable testosterone levels. J Gerontol A-Biol. 2001;56(5):M266-72.

69. Gianatti EJ, Dupuis P, Hoermann R, et al. Effect of testosterone treatment on constitutional and sexual symptoms in men with type 2 diabetes in a randomized, placebo-controlled clinical trial. J Clin Endocrinol Metab. 2014; 99(10):3821-8

70. Sinclair M, Grossmann M, Hoermann R, et al. Testosterone therapy increases muscle mass in men with cirrhosis and low testosterone: a randomised controlled trial. J Hepatol. 2016;65(5):906-13.

71. Frederiksen L, Glintborg D, Hojlund K, et al. Osteoprotegerin levels decrease during testosterone therapy in aging men and are associated with changed distribution of regional fat. Horm Metab Res. 2013;45(4):308-13.

72. Mohamad NV, Soelaiman IN, Chin KY. A concise review of testosterone and bone health. Clin Interv Aging. 2016;11:1317-24

73. Guo C, Gu W, Liu M, et al. Efficacy and safety of testosterone replacement therapy in men with hypogonadism: a meta-analysis study of placebocontrolled trials. Exp Ther Med. 2016;11(3):853-63.

74. Rastrelli G, Maggi M, Corona G. Pharmacological management of late-onset hypogonadism. Expert Rev Clin Pharmacol. 2018;11(4):439-58.

75. Junjie W, Dongsheng H, Lei S. Testosterone replacement therapy has limited effect on increasing bone mass density in older men: a metaanalysis. Curr Pharm Des. 2019;25(1):73-84
76. Seftel AD, Kathrins M, Niederberger C. Critical update of the 2010 Endocrine Society clinical practice guidelines for male Hypogonadism: a systematic analysis. Mayo Clinic Proc. 2015;90(8):1104-15.

77. Bouloux P. Testim 1\% testosterone gel for the treatment of male hypogonadism. Clin Ther. 2005;27(3):286-9.

78. Debruyne FM, Behre HM, Roehrborn CG, et al. Testosterone treatment is not associated with increased risk of prostate cancer or worsening of lower urinary tract symptoms: prostate health outcomes in the registry of Hypogonadism in men. BJU Int. 2017;119(2):216-24.

79. Loeb S, Folkvaljon Y, Damber JE, Alukal J, Lambe M, Stattin P. Testosterone replacement therapy and risk of favorable and aggressive prostate Cancer. J Clin Oncol. 2017;35(13):1430-6.

80. Baillargeon J, Kuo Y-F, Fang X, Shahinian VB. Long-term exposure to testosterone therapy and the risk of high grade prostate cancer. J Urol. 2015:194:1612-6.

81. Park J, Cho SY, Jeong SH, Lee SB, Son H, Jeong H. Low testosterone level is an independent risk factor for high-grade prostate cancer detection at biopsy. BJU Int. 2015;118:230-5.

\section{Publisher's Note}

Springer Nature remains neutral with regard to jurisdictional claims in published maps and institutional affiliations.
Ready to submit your research? Choose BMC and benefit from:

- fast, convenient online submission

- thorough peer review by experienced researchers in your field

- rapid publication on acceptance

- support for research data, including large and complex data types

- gold Open Access which fosters wider collaboration and increased citations

- maximum visibility for your research: over $100 \mathrm{M}$ website views per year

At BMC, research is always in progress.

Learn more biomedcentral.com/submissions 